\title{
Impact of traumatic upper-extremity amputation on the outcome of injury caused by an antipersonnel improvised explosive device
}

\author{
Maj Shane A. Smith, MD, MSc \\ LCol Mark P. DaCambra, MD \\ LCol Vivian C. McAlister, MB
}

Accepted Oct. 2, 2018

\author{
Correspondence to: \\ S.A. Smith \\ Royal Canadian Medical Service \\ C4-211 University Hospital \\ London ON N5X 2S1 \\ shane.smith@Ihsc.on.ca
}

DOI: $10.1503 /$ cjs. 014518
Background: We have previously reported a higher than expected rate of upper-extremity amputation (UEA) in victims of an antipersonnel improvised explosive device (AP-IED) compared with a similar cohort injured by antipersonnel mines (APM). The goal of this study was to describe the rate, severity and impact of UAE caused by an AP-IED.

Methods: We analyzed a prospective database of 100 consecutive dismounted AP-IED victims with pattern 1 injuries to compare the outcomes of the cohort with UEA to that without.

Results: We found that UEA (8 above elbow, 19 below elbow, 1 through elbow, 3 hand, 15 digit(s)) was much more prevalent with AP-IED than with APM (40\% v. $6 \%, p<0.001)$. In addition, UEA was associated with a higher rate of multiple amputations $(39[98 \%]$ v. $32[53 \%], p<0.001)$, bilateral lower-extremity amputation (LEA; $33[82.5 \%]$ v. 30 [53.3\%], $p=0.003)$ and facial injury $(8[20 \%]$ v. 4 [6.4\%], $p=$ $0.044)$, but not with pelvic disruption (10 [25\%]), genitoperineal mutilation (19 $[48 \%])$, eye injury $(6[15 \%])$, or skull fracture $(6[15 \%])$. The fatality rate was higher in patients with UEA than in those without $(12[30 \%]$ v. $7[12 \%], p=0.022)$.

Conclusion: Upper-extremity amputation is more prevalent with AP-IED than APM. Presence of UEA is associated with more severe injury and increased risk of death in AP-IED victims. Upper-limb injury has significant consequences for rehabilitation from LEA, which universally accompanies UEA in AP-IED victims. Upper-extremity injury should be amenable to prevention by innovative personal protective equipment designed to protect the flexed elbow.

Contexte : Nous avons déjà fait état d'un taux plus élevé que prévu d'amputations des membres supérieurs (AMS) chez les victimes d'engins explosifs artisanaux (EEA) comparativement à une cohorte similaire blessée par des mines antipersonnel (MAP). L'objectif de cette étude est de décrire le taux, la gravité et l'impact des AMS causées par des EEA.

Méthodes : Nous avons analysé une base de données prospective de 100 victimes consécutives d'EEA alors qu'elles se trouvaient hors de leur véhicule et présentant des blessures de type 1 afin de comparer les résultats des cohortes ayant subi ou non des AMS.

Résultats : Nous avons constaté que l'AMS ( 8 au-dessus du coude, 19 sous le coude, 1 au niveau du coude, 3 mains et 15 doigts) était beaucoup plus prévalente avec les EEA qu'avec les MAP (40\% c. $6 \%, p<0,001)$. De plus, l'AMS a été associée à un taux plus élevé d'amputations multiples (39 [98\%] c. 32 [53\%], $p<$ $0,001)$, d'amputations bilatérales des membres inférieurs (AMI) (33 [82,5\%] c. 30 $[53,3 \%], p=0,003)$ et de blessures au visage (8 [20\%] c. $4[6,4 \%], p=0,044)$, mais non de blessures au bassin (10 [25\%]), de mutilations génitopérinéales (19 [48\%]), de blessures oculaires (6 [15\%]), ou de fractures du crâne (6 [15\%]). Le taux de létalité a été plus élevé chez les patients ayant subi une AMS que chez ceux qui n'en ont pas subi (12 [30\%] c. 7 [12\%], $p=0,022)$.

Conclusion : L'amputation des membres supérieurs est plus prévalente avec les EEA qu'avec les MAP. L'AMS est associée à des blessures plus graves et à un risque plus grand de décès chez les victimes d'un EEA. Les blessures aux membres supérieurs ont de graves conséquences sur la réadaptation nécessaire après l'AMI, qui accompagne presque toujours l'AMS chez les victimes d'un EEA. Les blessures aux membres supérieurs devraient pouvoir être évitées grâce à de l'équipement de protection individuelle novateur conçu pour protéger le coude fléchi. 
ecent conflicts have seen a shift in the way soldiers and civilians are injured. Blast injuries, specifically from improvised explosive devices (IEDs), are more common than gunshot wounds. ${ }^{1,2} \mathrm{We}$ have reported on the injury pattern of antipersonnel IEDs (AP-IEDs) and shown this type of weapon to have significantly more destructive power than conventional antipersonnel mines (APMs), resulting in more patients with multiple amputations and severe pelvic-perineal injury. ${ }^{3}$ We also noted a higher than expected rate of upper-extremity injury. ${ }^{3}$ This combination of severe lower-body mutilation with upper-limb dysfunction has not been seen frequently in previous wars and requires us to develop new medical responses for the acute, intermediate and long-term phases of care.

Upper-extremity injury has been reported before in association with the AP-IED. ${ }^{4-7}$ Andersen and colleagues ${ }^{7}$ analyzed the injury pattern of United States service members with multiple amputations, including the upper extremity, who were injured by IED while dismounted. The authors speculated the upper-extremity amputation (UEA) occurred on the nondominant side of a soldier holding their rifle in the low-ready position. ${ }^{7}$ Jacobs and colleagues $^{5}$ examined 103 consecutive patients who suffered a lower-limb injury from an IED and presented to the United Kingdom (UK) Role 3 facility in Helmand Province, Afghanistan. They proposed the Bastion Classification to characterize the severity of IED injury by the level of lower-limb amputation. They reported significant upper-limb injuries in 40 of the 103 casualties they studied; however, they did not characterize the nature of the upperlimb injuries. ${ }^{5}$ Morrison and colleagues ${ }^{8}$ used the UK Joint Theatre Trauma Registry to retrospectively examine patients who sustained a traumatic lower-leg amputation and showed that the higher the level of amputation, the greater the injury burden and mortality. However, they did not report the upper-limb injury and amputation rates. ${ }^{8}$

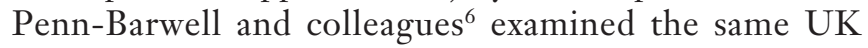
registry for patients who suffered bilateral lower-limb amputation. They found 43 patients with bilateral lowerlimb amputation, 9 of whom suffered an upper-limb amputation ( 3 below elbow and 6 above the elbow). ${ }^{6}$ Although the high rate of upper-extremity injury has been noted, the focus in the literature has been to characterize the lower-limb amputation pattern and associate this with severity of injury. We sought to describe the rate, severity and impact of UEA caused by AP-IEDs.

\section{Methods}

The present study used data from a cohort of patients treated at the North Atlantic Treaty Organization (NATO) Role 3 Multinational Medical Unit (R3-MMU) in Kandahar Air Field. The hospital received casualties from the point of injury or via a forward treatment cen- tre. ${ }^{10}$ An R3-MMU is the highest level of in-theatre medical care and would be equivalent to a civilian level-II trauma centre, as defined by the American College of Surgeons Committee on Trauma. Generally, coalition patients were transferred after damage-control surgery, whereas local patients also received definitive care at the R3-MMU. In order to minimize bias, patients were included sequentially as a consecutive series with a predefined definition of AP-IED target (International Committee of the Red Cross [ICRC] pattern 1 injuries). A specifically designated trauma nurse and attending surgeons prospectively collected data for each patient until the time of first discharge from hospital. Data were collected between January 2010 and July 2011, or until data from 100 victims had been obtained. We included pedestrian (dismounted) patients with pattern 1 APM injuries, defined by the ICRC as injuries that occur when the victim is close to the centre of the explosion, causing traumatic amputation. Patients with pattern 2 and 3 injuries, defined as fragmentation injuries and injuries caused by handling the AP-IED or APM, respectively, were excluded. Casualties that were nonpedestrian (i.e., in a vehicle) were also excluded. Eligible patients were identified for inclusion into the study when first responders reported IED as the mechanism of injury.

The specific aims of this study were to descriptively characterize the upper-extremity injuries of patients with AP-IED ICRC pattern 1 injuries, contrast the nature of concomitant injuries in patients with and without UEA, and compare the upper-extremity injury pattern of APIED to that of APM. The study was approved by the commander of the R3-MMU at Kandahar Air Field and by the Research Ethics Board of Western University (REB \# 104124).

\section{Statistical analysis}

Categorical data wee analyzed using the $\chi^{2}$ test. The APIED data were compared with previously published APM data. ${ }^{11}$

\section{RESULtS}

One hundred consecutive pedestrian casualties with ICRC pattern 1 injuries from AP-IEDs were identified, and their pattern of injury has been described previously. ${ }^{3}$ Forty of these casualties suffered UEA of the digits, hand or arm: 8 above elbow, 19 below elbow, 1 through elbow, 3 hand, and 15 instances of one or more finger amputations.

All AP-IED victims were male. The mean age of those with UEA was 24 (median 25, range 6-39) years. Five patients were younger than 18 years. Fourteen victims with UEA were Afghan local nationals and 19 were coalition soldiers, (USA, Canada, UK); the nationality of 7 victims was not captured (Table 1). 
Table 2 reports data for patients with and without UEA. All but 1 of the 40 patients (98\%) with UEA had other amputations: 5 (13\%) quadruple amputations, $29(73 \%)$ triple amputations and 5 (13\%) double amputations. Patients with UEA were more likely to have suffered multiple amputations than those without UEA (39 [98\%] v. 32 [53\%], $p<0.001)$. The lower-extremity amputation (LEA) was at a level above the knee in 17 (48\%) patients. Bilateral LEA was more prevalent in patients with UEA than in those without $(33[82.5 \%] \mathrm{v}$. $32[53 \%], p=0.003$ ).

Pelvic disruption and severe perineal, gluteal, or genital injuries occurred in $10(25 \%)$ and 19 (48\%), respectively, of the victims with arm amputation, which did not differ statistically from those without arm amputation. There were 5 rectal injuries, 3 penile injuries and 11 scrotal injuries, including 4 traumatic orchiectomies. Severe soft tissue injury was universal, with injection of contaminated soil along tissue planes well above entry sites and above the fracture level. Facial injuries, but not

Table 1. Demographic characteristics of victims injured by an antipersonnel improvised explosive device, according to the presence or otherwise of an upper-extremity amputation

\begin{tabular}{|lcc|}
\hline Characteristic & $\begin{array}{c}\text { Upper-extremity } \\
\text { amputation }\end{array}$ & $\begin{array}{c}\text { No upper-extremity } \\
\text { amputation }\end{array}$ \\
\hline No. of patients & 40 & 60 \\
\hline Age, yr, median (range) & $25(6-39)$ & $25(10-44)$ \\
\hline $\begin{array}{l}\text { Nationality, no. of } \\
\text { patients }\end{array}$ & & \\
\hline Afghanistan & 14 & 13 \\
\hline United States & 15 & 34 \\
\hline Canada & 0 & 8 \\
\hline United Kingdom & 4 & 0 \\
\hline Not specified & 7 & 5 \\
\hline
\end{tabular}

Table 2. Mortality and other clinical characteristics in victims injured by an antipersonnel improvised explosive device, according to the presence or otherwise of an upper-extremity amputation

\begin{tabular}{|lccc|}
\hline Characteristic & $\begin{array}{c}\text { Upper-extremity } \\
\text { amputation, no. (\%) } \\
n=40\end{array}$ & $\begin{array}{c}\text { No upper-extremity } \\
\text { amputation, no. (\%) } \\
n=60\end{array}$ & $p$ value \\
\hline Killed in action & $6(15)$ & $6(10)$ & 0.45 \\
\hline Died of wounds & $6(15)$ & $1(1.7)$ & 0.01 \\
\hline Total mortality & $12(30)$ & $7(11.7)$ & 0.022 \\
\hline Multiple amputations & $39(97.5)$ & $32(53.3)$ & $<0.001$ \\
\hline $\begin{array}{l}\text { Bilateral lower limb } \\
\text { amputations }\end{array}$ & $33(82.5)$ & $32(53.3)$ & 0.003 \\
\hline AKA or higher & $17(42.5)$ & $25(41.7)$ & 0.93 \\
\hline Pelvic fracture & $10(25)$ & $10(16.7)$ & 0.33 \\
\hline $\begin{array}{l}\text { Perineal/gluteal/ } \\
\text { genital injury }\end{array}$ & $19(47.5)$ & $27(45)$ & 0.81 \\
\hline Facial injuries & $8(20)$ & $4(6.7)$ & 0.044 \\
\hline Skull fracture & $6(15)$ & $4(6.7)$ & 0.17 \\
\hline Eye injuries & $6(15)$ & $6(10)$ & 0.45 \\
\hline AKA = above-knee amputation. & & \\
\hline
\end{tabular}

eye injury $6(15 \%)$ or skull fracture $6(15 \%)$, were more common in patients with arm amputation (8 [20\%] v. 4 [6.4\%], $p=0.044)$.

Six casualties were dead on arrival and another 6 died of their wounds despite treatment received at the R3-MMU. This generated a fatality rate of $30 \%$ for victims of ICRC pattern 1 injuries from an AP-IED who suffered a UEA; however, this is likely an underestimation, as some local national civilian casualties killed at the site of the AP-IED blast may not have presented to the R3-MMU. Patients with UEA were more likely to die of their wounds at the combat hospital than those without UEA (6 [15\%] v. 1 [1.7\%], $p=$ $0.01)$. The fatality rate was higher in patients with upper-limb amputations than in those without (12 $[30 \%]$ v. $7[12 \%], p=0.022)$.

\section{Discussion}

Andersen and colleagues ${ }^{7}$ coined the term "dismounted complex blast injury" to describe the pattern of injury caused by IEDs on dismounted soldiers in recent conflicts. Their description includes UEA in the cluster of devastating injuries caused by this type of weapon. The present study reports a rate of UEA with AP-IED (40\%) that is equivalent to that previously reported, ${ }^{5}$ but is significantly higher than that previously reported for ICRC pattern 1 injury victims of APM (6\%). ${ }^{11}$ This difference is almost certainly due to the greater destructive power of the AP-IED than the conventional APM., ${ }^{3,12}$ Victims of ICRC pattern 1 injuries from AP-IED have more severe injuries and are more likely to die if the blast causes a UEA. The increased fatality rate is also likely a consequence of higher explosive forces endured by the victim rather than hemorrhage from the upper extremity, which, of itself, can be controlled using standard tactical combat casualty care. Therefore, the presence of a UEA or mangled limb in a victim of an AP-IED may be a useful external sign to estimate severity of injury and to determine triage priority. Presence of a severely injured upper extremity should prompt a first responder to place a pelvic binder in addition to relevant tourniquets, as blood loss from this area is a likely cause of death. In comparison, the first responder should selectively apply a neck collar, as spine injury remains uncommon even if the force of the ground-based blast is sufficient to severely injure the upper extremity. ${ }^{13}$

Our findings have implications for the development of personal protective equipment (PPE). Coalition soldiers were equipped with truncal body armour, helmets and antiballistic eye protection. Each nation had its own variety of equipment. Afghan soldiers often used helmets, but their use of body armour was more inconsistent and they did not wear antiballistic eye protection. Civilian casualties were not wearing PPE. Heterogeneity in PPE 
use may have affected the pattern of injury observed in our study. Eye injuries were seen only in patients who were not wearing antiballistic eye protection. A lower proportion of coalition casualties of AP-IEDs, who wore full PPE, had upper-limb amputations than noncoalition casualties, whose use of PPE was incomplete and inconsistent. A particular injury that we noted involved loss of the bony elbow, sometimes with preservation of soft tissue anteriorly, which allowed for preservation of the forearm and hand (Fig. 1). ${ }^{14}$ Andersen and colleagues ${ }^{7}$ suggested this type of injury was due to the position of the nondominant side adopted by soldiers on patrol who were holding their rifle in the low-ready position. We did not find a difference in the rate of UEA between civilians and soldiers and are therefore unable to confirm their hypothesis. However, it seems likely that the injury is caused by the action of high-energy material on the flexed elbow, and therefore may be amenable to mitigation of the force by development of PPE specifically for the elbow in flexion.

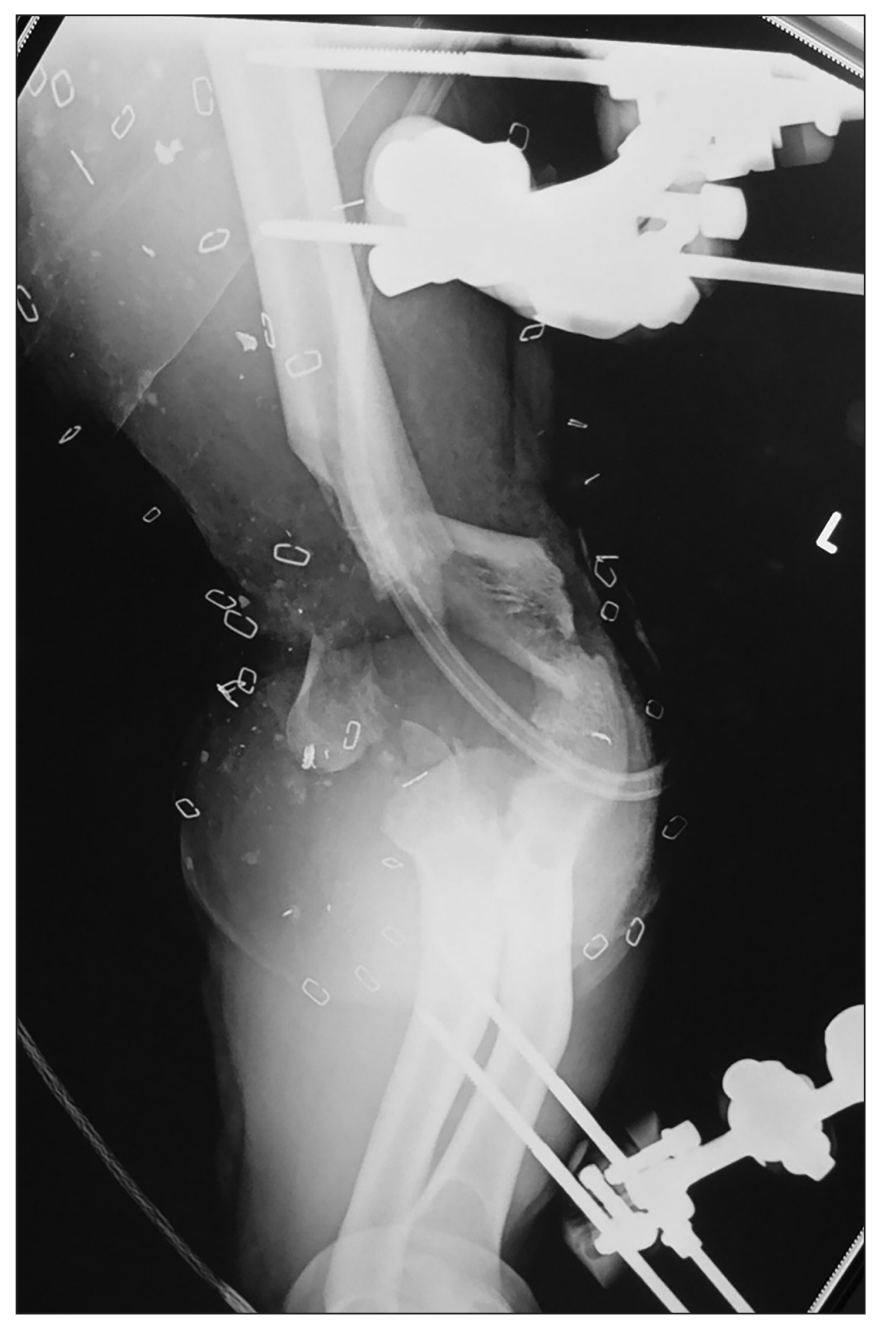

Fig. 1. Loss of the bony elbow with preservation of the forearm, possibly because of the flexed position at the time of injury from an antipersonnel improvised explosive device.
Cannon and colleagues 9 recently reviewed dismounted complex blast injuries. Damage-control surgical treatment of the upper extremity injured by AP-IED should focus on hemostasis, re-establishment of distal vascular flow, wound decontamination and stabilization/external fixation of orthopedic injuries. Choosing to undertake a limb salvage procedure can be difficult. If hemostasis can be obtained and vascular flow restored quickly, the decision to amputate should be deferred in the acute phase. Indices such as the Mangled Extremity Severity Score (MESS); Predictive Salvage Index (PSI); the Limb Injury Score (LIS); the Limb Salvage Index (LSI); the Mangled Extremity Syndrome Index; and the Nerve injury, Ischemia, Soft tissue injury, Skeletal injury, Shock and Age of patient (NISSSA) score are helpful to categorize the injury; however, they should not be used in isolation when deciding whether to undertake a limb-salvage procedure. The scores are generally found to have a low negative predictive value for amputation, and very few comprise factors specific to the upper extremity. ${ }^{15,16}$ In addition, neither the MESS nor any of the other available scores accurately predict functional outcomes in patients with severe limb trauma. ${ }^{17-19}$ Emergency amputation should be performed only if a limb is the source of uncontrollable, life-threatening bleeding, or if attempted salvage would pose unacceptable risk to the person's life. When hemostasis can be achieved, the decision of whether to amputate the damaged extremity or attempt limb-preserving surgery should be delayed along the route of evacuation until a multidisciplinary discussion involving orthoplastics, the rehabilitation specialist, the patient and their family is possible.

The high level of contamination of these wounds makes infection ubiquitous, contraindicating early placement of indwelling hardware. External fixation is a fast and safe method of providing orthopedic stability during often lengthy evacuation times and preventing further vascular injury without leaving indwelling hardware. Multiple operations may be required to remove the contamination from these wounds, and unusual and antibiotic-resistant soil organisms, such as Acinetobacter baumannii, can be encountered. ${ }^{20}$ Multiple surgeries may also be required to determine the extent of viable tissue. If there is too much soft tissue loss to accommodate vascularized graft coverage or too much bone loss to provide for options for orthopedic stability, amputation may be required. However, significant nerve injury should not preclude attempts at a limb-sparing approach.

The successful rehabilitation of patients with UEA is influenced by a variety of factors, including functional level of amputation, cognitive impairment, conditioning, nutritional status, social support, psychological factors and motivation. ${ }^{21}$ Given the premorbid physical fitness and determination of many deployed soldiers, they can be the ideal candidates to traverse the long rehabilitation 
course of a limb-sparing strategy. Combined upper and lower limb amputations and injury introduces unique challenges to complicate the rehabilitation process. These patients require early mobilization on lower-limb prostheses despite upper-limb injuries. Surprisingly, good rehabilitation can be achieved with muscular superdevelopment of which motivated, young and otherwise fit soldiers are capable. ${ }^{14,15,21}$ This option may not be available to them as they age, nor can it be used by victims, particularly civilians, who are older and more frail at the time of the injury.

\section{Conclusion}

All victims of AP-IEDs with UEA require lifelong support to cope with complex disabilities should they survive the initial trauma.

Affiliations: From the Royal Canadian Medical Service, Ottawa, Ont. (Smith, DaCambra, McAlister); and the Division of General Surgery, Western University, London, Ont. (Smith, McAlister).

Competing interests: None declared.

Contributors: S. Smith and M. DaCambra analyzed the data and wrote the manuscript. V. McAlister, the treating trauma surgeon, designed the study and revised the manuscript. All authors reviewed and approved the manuscript, had full access to all of the study data and agree to be responsible for the integrity of the data and the accuracy of the data analysis.

Data sharing: No additional data are available.

Disclaimer: The views expressed in this paper are those of the authors and do not constitute the views or policies of the Canadian Armed Forces.

\section{References}

1. Jacobs N, Taylor DM, Parker PJ. Changes in surgical workload at the JF Med Gp Role 3 Hospital, Camp Bastion, Afghanistan, November 2008-November 2010. Injury 2012;43:1037-40.

2. Beckett A, Pelletier P, Mamczak C, et al. Multidisciplinary trauma team care in Kandahar, Afghanistan: current injury patterns and care practices. Injury 2012;43:2072-7.

3. Smith S, Devine M, Taddeo J, et al. Injury profile suffered by targets of antipersonnel improvised explosive devices: prospective cohort study. BM7 Open 2017;7:e14697.

4. Fleming M, Waterman S, Dunne J, et al. Dismounted complex blast injuries: patterns of injuries and resource utilization associated with the multiple extremity amputee. 7 Surg Orthop Adv 2012;21:32-7.
5. Jacobs N, Rourke K, Rutherford J, et al. Lower limb injuries caused by improvised explosive devices: proposed 'Bastion classification' and prospective validation. Injury 2014;45:1422-8.

6. Penn-Barwell JG, Bennett PM, Kay A, et al. Acute bilateral leg amputation following combat injury in UK servicemen. Injury 2014:45:1105-10.

7. Andersen RC, Fleming M, Forsberg JA, et al. Dismounted complex blast injury. 7 Surg Orthop Adv 2012;21:2-7.

8. Morrison JJ, Hunt N, Midwinter M, et al. Associated injuries in casualties with traumatic lower extremity amputations caused by improvised explosive devices. Br 7 Surg 2012;99:362-6.

9. Cannon JW, Hofmann LJ, Glasgow SC, et al. Dismounted complex blast injuries: a comprehensive review of the modern combat experience. 7 Am Coll Surg 2016;223:652-664.e658.

10. Brisebois R, Hennecke P, Kao R, et al. The Role 3 Multinational Medical Unit at Kandahar Airfield 2005-2010. Can 7 Surg 2011; 54:S124-129.

11. Coupland RM, Korver A. Injuries from antipersonnel mines: the experience of the International Committee of the Red Cross. BMF 1991;303:1509-12.

12. Giannou C, Baldan M, Molde A. War surgery: working with limited resources in armed conflict and other situations of violence vol. 2. Geneva (Switzerland): International Committee of the Red Cross; 2013.

13. Taddeo J, Devine M, McAlister VC. Cervical spine injury in dismounted improvised explosive device trauma. Can 7 Surg 2011;58: S104-7.

14. McAlister V, Smith SA, Besemann M. Paths to recovery from a specific elbow injury from an anti-personnel improvised explosive device. NATO Science and Technology Organization; 2016.

14. Prichayudh S, Verananvattna A, Sriussadaporn S, et al. Management of upper extremity vascular injury: outcome related to the Mangled Extremity Severity Score. World 7 Surg 2009;33:857-63.

15. Slauterbeck JR, Britton C, Moneim MS, et al. Mangled extremity severity score: an accurate guide to treatment of the severely injured upper extremity. 7 Orthop Trauma 1994;8:282-5.

16. Bosse MJ, MacKenzie EJ, Kellam JF, et al. An analysis of outcomes of reconstruction or amputation after leg-threatening injuries. $N$ Engl 7 Med 2002;347:1924-31.

17. Ly TV, Travison TG, Castillo RC, et al. Ability of lower-extremity injury severity scores to predict functional outcome after limb salvage. 7 Bone foint Surg Am 2008;90:1738-43.

18. Busse JW, Jacobs CL, Swiontkowski MF, et al. Complex limb salvage or early amputation for severe lower-limb injury: a meta-analysis of observational studies. 7 Orthop Trauma 2007;21:70-6.

19. Bosse MJ, McCarthy ML, Jones AL, et al. The insensate foot following severe lower extremity trauma: An indication for amputation? 7 Bone foint Surg Am 2005;87:2601-8.

20. O'Shea MK. Acinetobacter in modern warfare. Int 7 Antimicrob Agents 2012;39:363-75.

21. The Management of Upper Extremity Amputation Rehabilitation Group. VA/DoD Clinical Practice Guideline for Management of Upper Extremity Amputation Rebabilitation. Washington (DC): Department of Veterans Affairs, Department of Defence; 2014. 